\title{
Evaluation of food safety problems based on the fuzzy comprehensive analysis method
}

\author{
Yingwen $\mathrm{ZHAO}^{1}$ (D), Muhammad TALHA ${ }^{2}$
}

\begin{abstract}
To preserve life and promote health, it is critical to have access to appropriate quantities of safe food. Foodborne illness is an infectious illness or poisoning caused by viruses, bacteria, or chemicals that contaminate food or water. Food safety and health are the responsibility of everyone, from the agricultural chain to the consumer who comes into touch with food, in order to limit the amount of food poisonings. Nutritionists feel that the home, or the location where the consumer prepares food, is one of the least supervised steps all the way from the farm to the table. Dr. Lotfi Zadeh invented fuzzy logic as a superset of classical logic. This article covers the mathematical foundations of fuzzy logic, as well as membership functions, fuzzy sets, and reasoning rules. Input numbers are converted into linguistic values by fuzzy expert systems, which are subsequently modified by if-then rules provided by a human expert. The notion of a fuzzy expert system is explored in-depth, along with its rule-base and set membership functions.
\end{abstract}

Keywords: safe food; poisoning; agricultural chain; fuzzy logic.

Practical Application: This article covers the mathematical foundations of fuzzy logic, as well as membership functions, fuzzy sets, and reasoning rules. Input numbers are converted into linguistic values by fuzzy expert systems, which are subsequently modified by if-then rules provided by a human expert. The notion of a fuzzy expert system is explored in-depth, along with its rule-base and set membership functions.

\section{Introduction}

While eating certain foods after exposure to the virus will not prevent the disease, getting enough vitamins and minerals from your daily diet is a key factor in keeping your immune system strong. Then, the immune system can fight the disease well, potentially reduce its severity, and speed up the healing process (El-Khalek, 2018; Gaggìa et al., 2010). The United States has the safest food resources in the world. However, it is estimated that between 25,000 and 250 million diseases and 10,000 deaths from contaminated food occur each year. It includes the food production chain from farm to retail, and it is in this chain, food may be contaminated or mismanaged. Therefore, all food production sites should be well monitored and controlled to reduce the risk of foodborne transmission. Many foodborne illnesses occur due to malnutrition in food services and retail stores. Since the food prepared in these facilities is the closest to the consumer's swallowing, monitoring and controlling the risks transmitted through Food is at its most critical in the foodservice and food retailers at the end of food production (Franz et al., 2019; Fung et al., 2018; Lee \& Yoon, 2021).

The 7th of June is World Food Safety Day, and Its goal is to bring attention to this problem and encourage the implementation of measures aimed at preventing, identifying, and reducing the risks of foodborne diseases and helping to improved food safety, agricultural growth, economic success, health protection, increased market access, increased tourism and sustainable development in general. The World Health Organization (WHO) and the united nations Food and Agriculture Organization (FAO) have joined forces to celebrate World Food Safety Day, together with member countries and other relevant organizations (Han et al., 2021; Kamboj et al., 2020; Wertheim-Heck et al., 2019; Elsheikh, 2020; Singh et al., 2020; Malla \& Brewin, 2020). The active thematic campaign "Food Safety Is Everyone's Business" aims to raise awareness of food safety issues around the world and calls for action from countries, the private sector, decision-makers, UN organizations, civil society, and the general public. Food safety is influenced by how it is produced, stored, processed, and eaten. Live bacteria can grow and reproduce in a vegetative state. There are few bacteria that can change state and become spores. Spores are produced When the conditions are unfavorable for the growth of bacteria, and the spores can not grow or reproduce. Instead, the spores protect the bacteria in an environment where they cannot grow. Bacteria are usually classified according to their growth requirements and are divided into two groups of microorganisms that cause spoilage and pathogenesis. The microorganisms cause the spoilage of food and spoil their color and smell. Pathogenic bacteria cause disease, and if people eat them, they get sick. Both of these bacteria are important in the preparation and serving of food. Because pathogens affect food safety, more emphasis is placed on them. However, keep in mind that more effort to make food safer will also lead to better food quality. Bacteria have different heat needs to grow (Nayak \& Waterson, 2019; Walls et al., 2019). 
States, producers, and consumers all have responsibilities for food safety. Everyone who comes into contact with food on its journey from farm to table has a unique responsibility to ensure that it is safe and nutritious (Cole et al., 2018; Garcia et al., 2019).

To cut down on the amount of food poisonings, everyone, anywhere from the farm chain to the consumer who comes in contact with food, is responsible for food safety and health. Nutritionists believe that one of the steps that are less controlled from the farm to the time of consumption is the home or, in fact, the place where the consumer prepares food (Biré et al., 2020; Colombo et al., 2018; Sonchieu et al., 2018). The idea comes from the idea that food is dangerous under natural conditions, but given the information that is now available on issues with food safety, a variety of technologies can be used to produce healthier foods. Appeared. Food industry companies that produce packaged foods used in restaurants have access to this kind of knowledge and technology, although many consumers may not be aware of it. When sensory evaluators consumed home-cooked food that was prepared in the same way as a restaurant, surveys showed that 99 percent of home-cooked food was rejected. There are simple food safety rules in the home that can be followed to reduce the risk of getting sick after eating. In this regard, the care of the story begins, and it must be ensured that no water from the raw meat that is cooked later is poured on fresh and raw fruits and vegetables.

If there is a concern about contaminating food with raw meat, you can buy pre-cooked meat, but you will have to pay more for it. A good food safety idea in the store is to pay attention to the expiration date. Damaged packages can be intentionally or accidentally contaminated with food (Han, 2009; Karimi et al., 2018; Kumar et al., 2020; Anil \& Bhat, 2020). Therefore, after buying food and putting it in the vehicle, we must make sure that we are not the cause of misuse of food. Fresh food spoils quickly in hot weather. So, it is better not to stop at another place after buying from the store. Highly perishable foods such as raw meat should not be refrigerated for more than an hour. Perishable foods that stay out of the refrigerator longer at room temperature spoil faster and pose greater health risks. Once you get home, it is important to break down perishable foods quickly. Again, it is important to check that the raw broth does not come into contact with other foods. Care should also be taken to keep food out of the reach of pets.

\subsection{Factors that frequently cause food poisoning}

Cross-contamination, poor personal hygiene, inappropriate storage temperature, cooking at extremely low temperatures, and food from hazardous sources are only a few of them. Personal hygiene must be observed before and during food preparation, which means that hands must be washed before food transfer, and all items that come into touch with food must be sanitized. Frequent hand washing while preparing food, especially after contact with raw meat and eggs that are not fully cooked, is a good idea.

Towels used for hands and surfaces should never be used to dry dishes (Kennedy et al., 2005; Medeiros et al., 2001; Corches et al., 2020; Schroeder et al., 2020). Surfaces and chopping boards used for raw meat should not be used unless they are washed and cleaned between each use. Adequate cooking is required to kill harmful germs in raw foods. When the food is finished, the food should be discarded, but not in the can prepared. It should be noted that cooking due to contamination and improper storage can accelerate the growth of harmful microbes, but proper storage in the refrigerator reduces the growth rate of harmful microbes in food waste. It takes a long time for food to cooling, allowing harmful germs to grow. Therefore, hot foods should be transferred to shallow containers and cooled immediately.

\subsection{Food safety in a changing world}

Safe food contributes to the development of tourism, trade, and national economies. The number of individuals buying and eating food cooked in public areas is increasing as a result of urbanization and consumption patterns, particularly the development of tourism. In the context of globalization, the demand for an ever-wider range of food products is growing, which leads to the complication and lengthening of the global food chain (Imathiu, 2017; Tirado et al., 2010).

With a growing global population and food demand, the crop and livestock sectors are increasing in intensity and industrialization, creating new opportunities and new threats to food safety. Food safety is also expected to suffer as a result of climate change.

To maintain food safety, all of these problems put additional responsibilities on food producers and employees. Over the last decade, major outbreaks of foodborne disease have occurred on every continent, frequently worsened by the influence of globalization on world commerce (Matle et al., 2019; Smith et al., 2019).

Over 200 illnesses are caused by parasites, viruses, pathogenic bacteria, or toxins found in food. New risks to food safety emerge on a regular basis: environmental changes, bacterial resistance, and changes in food production, distribution, and consumption. WHO published five essential principles for safe food (Marriott et al., 2006):

- Make sure the food is clean.

- Keep raw and cooked foods separate.

- Make sure all meals are completely cooked.

- Make sure your meal is cooked at the correct temperature.

- Consume only safe raw foods and drink only safe water.

Food safety and health are some of the most important issues in the field of health of society; According to the latest figures from the World Health Organization, at least 600 million foodborne illnesses cause disease worldwide each year, and unfortunately, 420,000 people die from foodborne illness. Thus, deaths due to foodborne illnesses cause many casualties in the world. Among foodborne diseases, infectious agents that cause diarrhea are still the most important causes of disease worldwide, although the role of chemical contaminants and their risks in ensuring food safety is also of particular importance (Fajardo et al., 2013). 
Enterohaemorrhagic Escherichia coli, Campylobacter, and Salmonella, are among the most prevalent foodborne infections, infecting thousands of people each year. The illnesses produced by these bacteria can be severe and deadly in some circumstances (Anderson et al., 2014; Hascelik et al., 1991). Food safety is a vital part of food security and nutrition, which in turn is achieved when people at all times have access to food, both physically and economically, that meets their dietary needs with the goal of having a Life an active and healthy life (Allerberger et al., 2003; Karch et al., 2005). The Food and Agriculture Organization of the United Nations (FAO), jointly with the World Health Organization, celebrates World Food Safety Day to draw public attention and inspire action to prevent, detect, and manage food hazards and play a role in security. Food, human health, economic prosperity, agriculture, and sustainable development were cherished. The Alimentarius Codec Commission, administered by FAO and the World Health Organization, provides standards, guidelines, and principles for practical knowledge-based guidance aimed at ensuring food safety and quality by addressing issues such as refineries, health regulations, labeling, additives, inspections and licenses, nutrients and residues of veterinary drugs and pesticides (Fazal-ur-Rehman, 2019; Mishra, 2008). The FAO and the World Health Organization encourage all policymakers to promote agriculture and sustainable food systems. Support appropriate agricultural practices to provide adequate safe food. They emphasize the importance of empowering consumers to make healthy food choices and the universal and shared responsibility to work together on such an important issue that affects our lives. The United Nations General Assembly adopted a resolution on December 20, 2018, designating June 7, 2019, as the first commemoration of World Food Safety Day.

Man needs the energy to do his work, and this energy must be obtained from healthy and nutritious food. If food is exposed to contamination and spoilage, it can endanger human health because food contains nutrients, and microbes also need nutrients to grow, so food can be a source of disease. We need to know about foods, ways of contaminating foods, how to store them, the principles of fighting germs and pathogens so that we can understand the diseases caused by the consumption of contaminated foods such as poisoning, parasitic diseases such as worms, and who to prevent. Bacteria, fungal toxins, molds, chemicals, drugs, and pesticides can cause contamination and spoilage of food, so we need to know how to consume food to prevent poisoning and disease. According to the World Health Organization, more than two million people die each year from contaminated food and water, most of them children, because their immune systems are weaker than those of adults. The most important sources of food contamination are uncooked animal proteins and vegetables and fruits that have not been disinfected.

There are about 200 foodborne diseases transmitted to humans. Salmonella, Escherichia coli (E. coli), and Campylobacter are the most important foodborne pathogens. Long-term chemical pollution can lead to a variety of poisonings and diseases such as cancer.

Foods fall into three categories in terms of spoilage rate, including highly perishable foods such as milk, meat, fish, poultry, eggs, and other animal foods that should only be refrigerated for a short time. Maintained. Semi-perishable foods, including vegetables and fruits, can be stored in the cool air outside the refrigerator for a short time and should be refrigerated in hot weather. The third category is perishable foods such as legumes and grains of dry cereals (wheat and rice) that can be stored in good conditions for a long time. Food handlers who have been infected with the virus are frequently the source of contamination (Khalili \& Sharifi-Mood, 2016; Shuval, 2003) (Figure 1).

Contamination and spoilage of food can cause many problems for people; if food, especially cooked food, is not stored well, it can cause food poisoning, which is a symptom of vomiting and diarrhea. Foodborne illnesses occur in two forms, some of which include food poisoning, which causes symptoms due to contamination of food with bacteria, viruses, and other pathogens (due to lack of hygiene). Poisoning is one of the diseases that can lead to death due to severe diarrhea and vomiting (Adeyeye, 2016; Bhat \& Vasanthi, 2003; Vasanthi \& Bhat, 1998). The second category is caused by food contamination with various chemicals, fungal toxins, pesticides, heavy metals, and insecticides, the symptoms of which are manifested in the long run and if a person uses such foods for a long time. Exposed to diseases such as nerve damage, birth defects, and a variety of cancers. The germs that cause diarrheal diseases are usually transmitted to humans through contact with contaminated hands, including diarrhea and intestinal fever.

\section{Material and methods}

Today, the food industry is responsible for a large part of the preparation of food for the people. Due to the fact that these foods are produced in large quantities and consumed on a large scale, they can be an important source of foodborne illness, of which poisoning is a part. In the world, in order to control these diseases, special monitoring systems have been developed that are used during the production process. HACCP is one of these safety systems that has been developed in Iran, and all companies and food industries are required to comply with it. Establishing a HACCP system in the factory, like building any new structure, requires investment and high costs by the factory owners. Therefore, the need to create a coherent system for HACCP storage has led to the use of intelligent decisionmaking methods to provide a new way to advance the decision to build the HACCP of each product in the factory.

In many cases, accurate information and certain data are insufficient to model the actual situation because individuals' judgments are usually vague, and precise numerical values are not used to express opinions. In order to overcome such inaccurate thinking, Professor Lotfizadeh introduced the theory of fuzzy sets, the main innovation of which is to make it possible to display inaccurate and ambiguous concepts. And in decision-making systems, because the individual's opinions are ambiguous, the best way to use the individual's information is to express it using fuzzy logic (Gong \& Jin, 2009; Ji et al., 2000). The term "fuzzy" was used to describe something that was both imprecise and ambiguous. In everyday life, we occasionally come into circumstances in which we are unsure whether we are making the correct or wrong option, and the proper action is concealed from our view. "Fuzzy Logic" makes a sensible and beneficial argument at this point. 


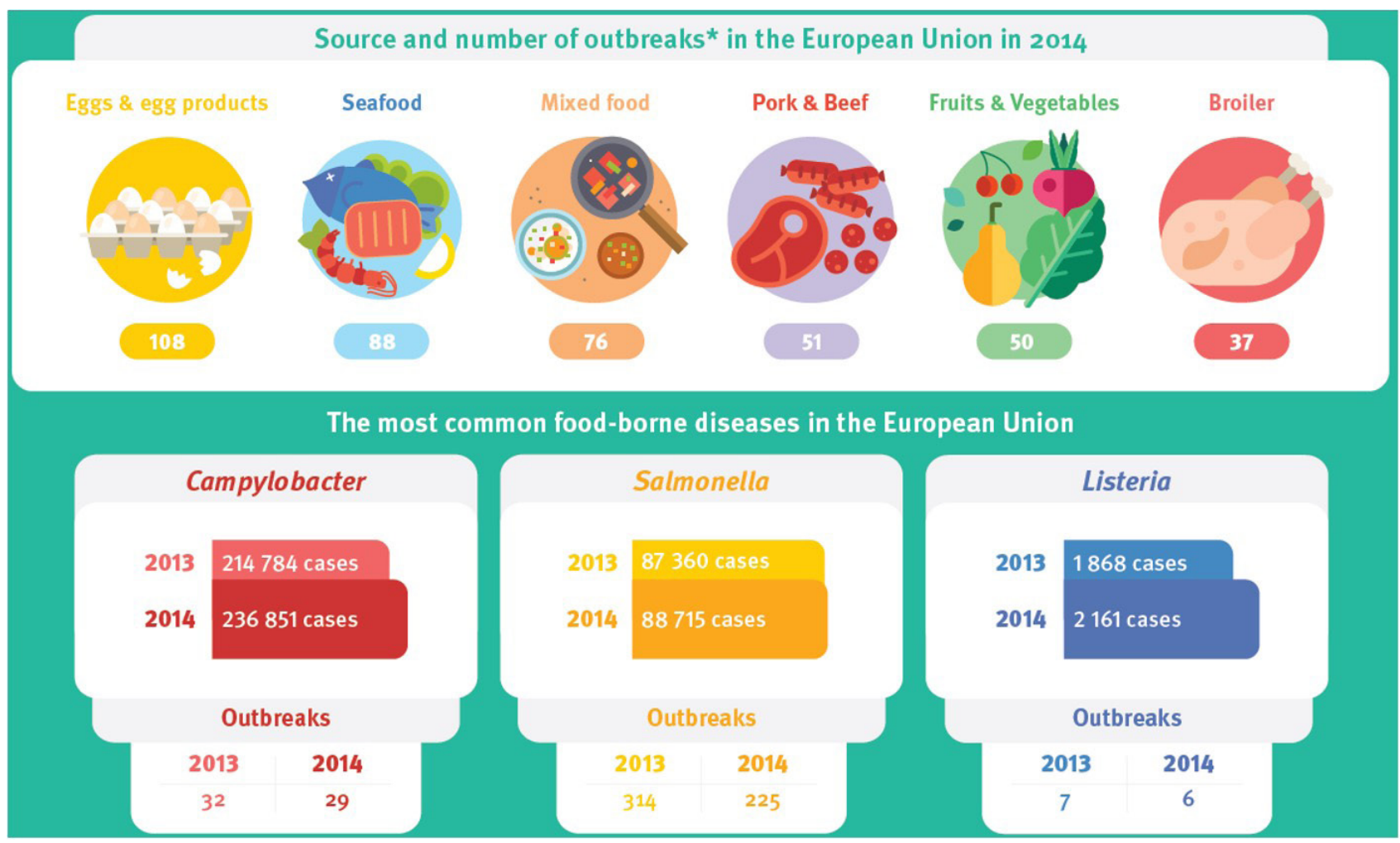

Figure 1. The causative agents of food poisoning in the European Union, in terms of the number of outbreaks.

In this approach, the level of uncertainty in any circumstance may be assessed. As a result, fuzzy logic is sometimes referred to as skeptical logic because of its skepticism-inducing effects. Fuzzy logic has helped to address many decision-making issues today, and it delivers the optimal conclusion based on inputs in the vast majority of instances (Chen et al., 2015; Feng \& Xu, 1999). Fuzzy logic is a development of Aristotle or boolean logic that is based on human judgments. Fuzzy arithmetic, fuzzy numbers, and even statistical fuzzy tools like fuzzy clustering have all been built using fuzzy logic. Technologies and computers are being developed that outperform similar devices based on Boolean logic. Although the notion and research of fuzzy logic date back to 1920, Professor Lotfi Zadeh (1921-2017) coined the fuzzy name logic in 1965 at Berkeley University. (Angelov, 2018; Seising, 2019). He recognized that digital technologies do not have the capacity to mimic the thoughts and ideas of the human mind and cannot reason like humans since digital logic only has two states for each choice, True and False. False because human reasoning involves a degree of right or wrong in making a decision. Instead of evaluating two scenarios, such as black or white, the fuzzy logic method considers a spectrum of gray that is confined to white on one side and black on the other (McNeill \& Thro, 2014). Artificial intelligence and control theory, for example, both employ fuzzy logic. Computers can perform computations and judgments based on ambiguous and implicit input using fuzzy logic in various domains.

\subsection{Fuzzy set}

Learning fuzzy logic begins with an understanding of the idea of a fuzzy set. To put it another way, fuzzy logic may be debated using fuzzy sets. Fuzzy collections can be explained in comparison with classic collections and the concept of membership degree. In a classical set, each component of the set has a membership rank of one, and the other elements have a membership rank of zero. Fuzzy sets, unlike classical sets, do not have well-defined boundaries (Deschrijver \& Kerre, 2003; Zimmermann, 2011).

For example, according to the classical school, a student who gets a score of 9.5 is placed in the rejected set, and a student who gets a score of 10.5 is placed in the accepted set. Now the question arises: is the difference between the two so great that the first person should be equally behind the second person? Such a definition of an absolute threshold value for the inclusion of individuals in a set is embedded in classical logic. Fuzzy logic has introduced new essential concepts into mathematics and logic in the form of uncertainty and ambiguity and has transformed the foundations of classical science. The key to understanding the fuzzy set is the concept of "membership degree."

\subsection{Degree of membership}

Another degree of membership is the focal concept of fuzzy logic. In his article, Lotfizadeh used the example of human height to explain the concept of fuzzy logic, in which he used the concept of "membership curve." This curve determines the degree of membership for the size of the height. Lotfizadeh's membership curve works just like the curve provided by Black (Zadeh, 1983, 1995, 1996b, 1996a).

In classical logic, the belonging or membership of a member to a conceptual set is quite definite and precise. So, an 
object or a member of a set or not. As a result, there are only two possible results for the membership function: 0 and 1 . In order to describe the gradual and slight changes, Lotfizadeh has introduced degrees between 0 and 1 and the concept of membership degree or membership function. For this purpose, the membership function $\mu$ is defined, which always contains values of the interval [0 and 1] (Shongwe et al., 2020).

\subsection{Fuzzy numbers}

Each number is a definite value in classical logic, but each number is an approximate value in fuzzy logic. The following three conditions make sure that a fuzzy number belongs to a fuzzy set (Kumar \& Kaur, 2011; Wang \& Li, 2017):

- Be normal

- Be convex

- Its backup collection is limited.

A wide variety of fuzzy numbers with different names and properties have been proposed and used. But an important principle in applying fuzzy theory is its computational efficiency. There are many difficulties in working with different fuzzy numbers. To solve this problem, a study introduced the "right and left" fuzzy numbers called L-R numbers (Figure 2) (Dubois \& Prade, 1978). But this method also has many complexities and is less used. Among these, triangular and trapezoidal fuzzy numbers are the most used. These numbers are widely used in social sciences and management.

\subsection{Fuzzy logic discussion summary}

The use of fuzzy sets in decision-making is one of the most important applications of this theory compared to classical theories. In fact, fuzzy decision theory tries to establish the

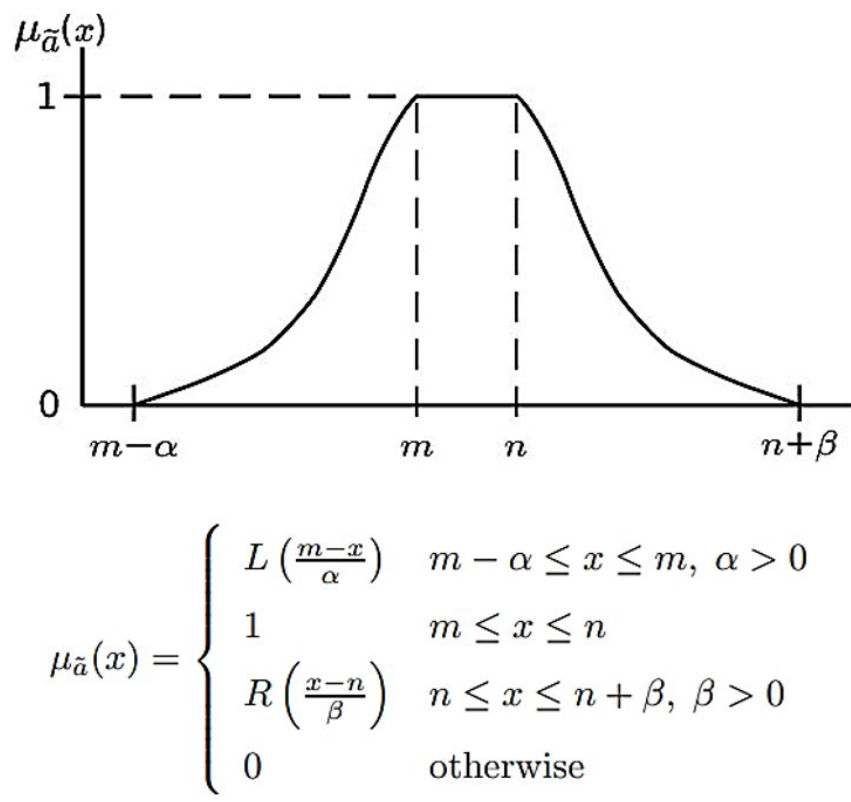

Figure 2. Graphical representation of an L-R fuzzy number. inherent ambiguity and uncertainties in the preferences, goals, and limitations of decision problems in the model. In decisionmaking models, it is always better than the decision to be less dependent on the system of two yes-no answers because if the answer is incorrect, the error will be $100 \%$, and this error will have a great effect on the decision-making model (Figure 3).

Although experts' skills and mental capacities are utilized to draw comparisons in multi-criteria decision-making techniques, quantifying expert opinions in the usual fashion does not fully reflect the nature of human thinking. Fuzzy sets are better for making real-world judgments because they are more consistent with linguistic and often confusing human explanations.

\section{Results and discussion}

An intelligent system entails gathering and individual encoding information concerning classification and prediction and a rule basis evaluation engine for a particular set of inputs (Iqbal et al., 2017; Ramos et al., 2020).

A fuzzy inference engine, a set of fuzzy membership functions, and a set of fuzzy rules are the core components of a fuzzy expert system. They're utilized in a variety of disciplines, including data analysis, financial systems, pattern recognition, linear and nonlinear control. A scheduler is included in the fuzzy inference engine, which picks the rules in a sequence for processing. A scheduler is needed because certain rules must be checked before others. Some rules fire and make their consequents true. Certain rules have antecedents, and these consequents are the antecedents of those rules. As a result, a scheduler must implement a firing order. It also has a rule processor that checks the truth values of the conditions on the left-hand side of a rule. It fires the rule based on these truth values. A set membership builder uses approximation reasoning to create an approximate membership function for the result from the rules firing. The inferred fuzzy values of the consequents are then fuzzified to a non-fuzzy value. The expert system works as follows (Vadiati et al., 2019):

1. Fuzzification: This procedure entails determining the degrees of membership of linguistic values in a linguistic variable that corresponds to a user or process input value. The degree of truth for each rule antecedent may be determined by applying membership functions to the input values.

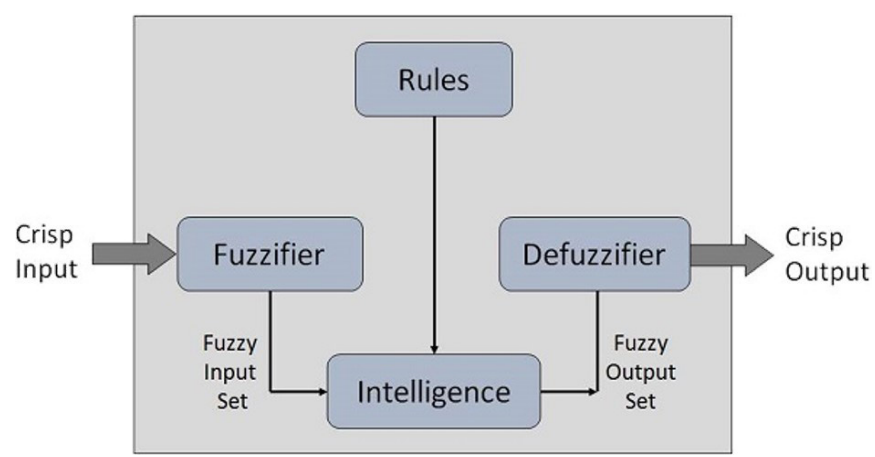

Figure 3. Fuzzy logic system. 
2. Inference: The truth values of the linguistic values are used to compute the truth values of each rule after the if-then rules are implemented. As already stated, approximate reasoning is employed. Min and product are two often used inference rules. In min inferencing, the output membership function is decided by the implemented rule's true value or the membership function's original value, whichever is lower. The output membership function is scaled by the truth value of the rule premise in product inferencing.

3. Composition: Each output linguistic variable's fuzzy subsets are merged to produce a single fuzzy subset. Max and sum are the approaches that are employed. The fuzzy sets for the output variable are ORed together in max composition such that the maximum value from all of the fuzzy subsets is utilized. The fuzzy subsets associated with the output value are added to produce a single fuzzy subset in sum composition.

4. Defuzzification: De-fuzzy is a method of converting fuzzy numbers to crisp numbers. This operation makes the results of the fuzzy inference understandable to the audience. Depending on the scope of application, various fuzzy decoupling methods have been proposed. The goal of all these methods is to convert fuzzy results to non-fuzzy or ordinary results. In a fuzzy system, fuzzy input elements are used first. After that, the calculations are done in a fuzzy way. Finally, the results should be defuzzy. By defragging the results of a fuzzy computing system, reports can be presented in an understandable way to their users. Once the appropriate fuzzy spectrum has been selected, and the fuzzy operations have been performed on the values, you will finally arrive at results that will normally be fuzzy. These fuzzy results are not easy to understand and interpret, so they must be converted to definite (ordinary) numbers. The process of converting fuzzy numbers to definite numbers is called defuzzification.

\subsection{Implementation of a simple fuzzy expert system}

To demonstrate the use of fuzzy expert systems, a fuzzy washing machine is implemented. The details of the system were obtained from reference.

1. Developing membership functions: The washing machine receives input from the user in the form of scalar values on a scale of 1 to 10. These correspond to two linguistic variables, "degree of dirtiness" and "type of dirt." Each has 3 linguistic values, Degree of dirtiness $\left(D_{d}\right)=\{$ Low, Medium, High $\}=\left\{\mu_{L O W}, \mu_{M E D}, \mu_{H I}\right\}$ and Type of $\operatorname{dirt}\left(\mathrm{D}_{\mathrm{t}}\right)=$ $\{$ Not greasy, Medium greasy, Greasy $\}=\left\{\mu_{N G}, \mu_{M G}, \mu_{G}\right\}$. The expected output from the expert system is the linguistic variable "duration of the wash cycle $\left(\mathrm{W}_{\mathrm{d}}\right)$," ranging from 0 to 60 minutes. The linguistic values for the output are $\mathrm{W}_{\mathrm{d}}=\{$ Very short, Short, Medium, Long, Very long $\}=$ $\left\{\mu_{V L}, \mu_{L}, \mu_{M}, \mu_{S}, \mu_{V S}\right\}$. The linguistic variables are the fuzzy sets, and each of the 11 linguistic values ( 6 for the inputs and 5 for the outputs) are fuzzy membership functions.
2. Developing the rule-base: We have two inputs comprising three membership functions each. Thus, we will have $3 \times 3=9$ rules of inference comprising the rule base.

If degree of dirtiness is High and the type of dirt is Greasy, then the duration of the wash cycle is Very long;

If degree of dirtiness is Medium and type of dirt is Greasy, then duration of wash cycle is Long;

If degree of dirtiness is Low and type of dirt is Greasy, then duration of wash cycle is Long;

If degree of dirtiness is High and type of dirt is Medium, then duration of wash cycle is Long;

If degree of dirtiness is Medium and type of dirt is Medium, then duration of wash cycle is Medium;

If degree of dirtiness is Low and type of dirt is Medium, then duration of wash cycle is Medium;

If degree of dirtiness is High and type of dirt is not greasy, then duration of wash cycle is Medium;

If degree of dirtiness is Medium and type of dirt is not greasy, then duration of wash cycle is Short;

If degree of dirtiness is Low and type of dirt is not greasy, then duration of wash cycle is Very short

Since none of the above rules depending on the firing on any of the other rules, a scheduler for firing rules is not needed.

3. The expert system algorithm (Figure 4):

- Accept user inputs from an interface. These are values on a scale of 1 to 10 .

- Fuzzify the inputs, i.e., determine the membership values in each of the six membership functions for both inputs.

- Apply the membership values of the inputs to the rule-base to generate the truth values of the nine rules' consequences.

- Use MIN inferencing to generate new output membership functions. The new membership values are compared pointwise to the original membership functions to get the modified output membership functions

- Combine the new membership functions to form a single membership function using the MAX composition method. In this, all the newly generated membership functions are

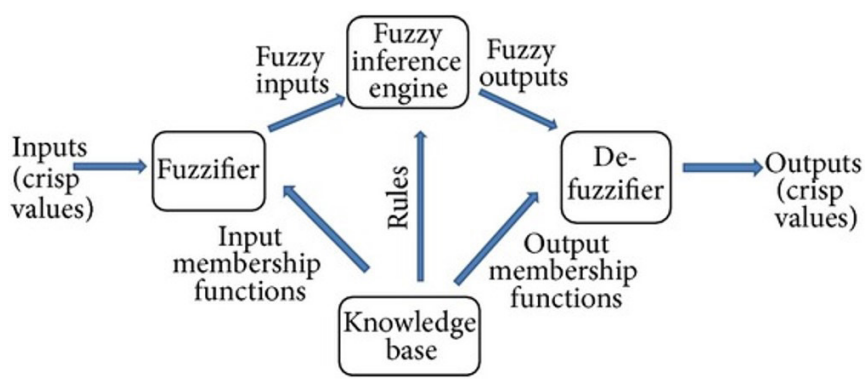

Figure 4. Outline of a basic fuzzy expert system. 
combined with each other using the fuzzy OR, and the maximum possible membership value is chosen for each output value.

Perform defuzzification using the centroid method to get a scalar output value for the actual duration of the wash cycle.

\section{Conclusion}

Bacteria that grow in food are food born and use plants as vectors in animal host populations. The plant bacterium Salmonella and the pathogen Escherichia coli and other related pathogens have such production characteristics. Common bacterial contaminants in the environment are usually expressed through contact with plants. By entering and reaching plants, these pathogens can survive and cause disease in humans. In this descriptive article, the importance of the process of human pathogen mechanisms for plant colonization, expressing their biological relationship, and recognizing the effective factors in reducing the population of pathogens and the role of plants and other factors in this field are discussed.

Predicting the performance of agricultural products plays an important role in determining food policy. This study investigated how to use an adaptive neuro-fuzzy inference system (ANFIS) and artificial neural network MLP in predicting food production, and their efficiency in predicting soybean yield in dryland conditions has been compared.

\section{References}

Adeyeye, S. A. (2016). Fungal mycotoxins in foods: a review. Cogent Food \& Agriculture, 2(1), 1213127. http://dx.doi.org/10.1080/2331 1932.2016.1213127.

Allerberger, F., Friedrich, A. W., Grif, K., Dierich, M. P., Dornbusch, H.-R., Mache, C. J., Nachbaur, E., Freilinger, M., Rieck, P., Wagner, M., Caprioli, A., Karch, H., \& Zimmerhackl, L. B. (2003). Hemolyticuremic syndrome associated with enterohemorrhagic Escherichia coli O26: $\mathrm{H}$ infection and consumption of unpasteurized cow's milk. International Journal of Infectious Diseases, 7(1), 42-45. http://dx.doi. org/10.1016/S1201-9712(03)90041-5. PMid:12718809.

Anderson, N. W., Buchan, B. W., \& Ledeboer, N. A. (2014). Comparison of the BD MAX enteric bacterial panel to routine culture methods for detection of Campylobacter, enterohemorrhagic Escherichia coli (O157), Salmonella, and Shigella isolates in preserved stool specimens. Journal of Clinical Microbiology, 52(4), 1222-1224. http:// dx.doi.org/10.1128/JCM.03099-13. PMid:24430460.

Angelov, P. (2018). How best to design Fuzzy Sets and Systems. In R. Fullér, S. Giove, \& F. Masulli (Eds.), International Workshop on Fuzzy Logic and Applications (pp. 236-239). Genova: Springer.

Anil, M. A., \& Bhat, J. S. (2020). Transitional changes in cognitivecommunicative abilities in adolescents: a literature review. Journal of Natural Science, Biology, and Medicine, 11(2), 85.

Bhat, R. V., \& Vasanthi, S. (2003). Mycotoxin food safety risk in developing countries. Food Safety in Food Security and Food Trade 2020 Vision Briefs, 10(3)

Biré, R., Bertin, T., Dom, I., Hort, V., Schmitt, C., Diogène, J., Lemée, R., Haro, L., \& Nicolas, M. (2020). First evidence of the presence of anatoxin-a in sea figs associated with human food poisonings in France. Marine Drugs, 18(6), 285. http://dx.doi.org/10.3390/ md18060285. PMid:32485965.
Chen, J., Hsieh, H., \& Do, Q. H. (2015). Evaluating teaching performance based on fuzzy AHP and comprehensive evaluation approach. Applied Soft Computing, 28, 100-108. http://dx.doi.org/10.1016/j. asoc.2014.11.050.

Cole, M. B., Augustin, M. A., Robertson, M. J., \& Manners, J. M. (2018). The science of food security. Npj Science of Food, 2(1), 14. http:// dx.doi.org/10.1038/s41538-018-0021-9. PMid:31304264.

Colombo, F. M., Cattaneo, P., Confalonieri, E., \& Bernardi, C. (2018). Histamine food poisonings: a systematic review and meta-analysis. Critical Reviews in Food Science and Nutrition, 58(7), 1131-1151. http://dx.doi.org/10.1080/10408398.2016.1242476. PMid:27791395.

Corches, C. L., McBride, A. C., Robles, M. C., Rehman, N., Bailey, S., Oliver, A., \& Skolarus, L. E. (2020). Development, adaptation and scale-up of a community-wide, health behavior theory-based stroke preparedness intervention. American Journal of Health Behavior, 44(6), 744-755. http://dx.doi.org/10.5993/AJHB.44.6.1. PMid:33081873.

Deschrijver, G., \& Kerre, E. E. (2003). On the relationship between some extensions of fuzzy set theory. Fuzzy Sets and Systems, 133(2), 227-235. http://dx.doi.org/10.1016/S0165-0114(02)00127-6.

Dubois, D., \& Prade, H. (1978). Operations on fuzzy numbers. International Journal of Systems Science, 9(6), 613-626. http://dx.doi. org/10.1080/00207727808941724.

El-Khalek, A. F A. (2018). Impact of some postharvest safe treatments on maintaining quality and extending life of Guava Fruits during cold storage. Egyptian Journal of Horticulture, 45(2), 237-256. http:// dx.doi.org/10.21608/ejoh.2018.3597.1064.

Elsheikh, M. A. A. (2020). Degradation kinetics Of carbofuran insecticide in tomato fruits. European Chemical Bulletin, 9(10-12), 355-359. http://dx.doi.org/10.17628/ecb.2020.9.355-359.

Fajardo, P., Atanassova, M., Cotterill, J., Wontner-Smith, T., Vieites, J., \& Cabado, A. (2013). Mitigation of pathogens and marine biotoxins contamination in shellfish. WIT Transactions on the Built Environment, 134, 691-698. http://dx.doi.org/10.2495/SAFE130621.

Fazal-ur-Rehman, M. (2019). Polluted water borne diseases: symptoms, causes, treatment and prevention. Journal of Medicinal and Chemical Sciences, 2(1), 21-26.

Feng, S., \& Xu, L. D. (1999). Decision support for fuzzy comprehensive evaluation of urban development. Fuzzy Sets and Systems, 105(1), 1-12. http://dx.doi.org/10.1016/S0165-0114(97)00229-7.

Franz, C., Besten, H. M., Boehnlein, C., Gareis, M., Zwietering, M. H., \& Fusco, V. (2019). Reprint of: microbial food safety in the 21st century: emerging challenges and foodborne pathogenic bacteria. Trends in Food Science \& Technology, 15, 34-37.

Fung, F., Wang, H.-S., \& Menon, S. (2018). Food safety in the 21st century. Biomedical Journal, 41(2), 88-95. http://dx.doi.org/10.1016/j. bj.2018.03.003. PMid:29866604.

Gaggìa, F., Mattarelli, P., \& Biavati, B. (2010). Probiotics and prebiotics in animal feeding for safe food production. International Journal of Food Microbiology, 141(Suppl. 1), S15-S28. http://dx.doi.org/10.1016/j. ijfoodmicro.2010.02.031. PMid:20382438.

Garcia, S. N., Osburn, B. I., \& Cullor, J. S. (2019). A one health perspective on dairy production and dairy food safety. One Health, 7, 100086. http://dx.doi.org/10.1016/j.onehlt.2019.100086. PMid:30911596.

Gong, L., \& Jin, C. (2009). Fuzzy comprehensive evaluation for carrying capacity of regional water resources. Water Resources Management, 23(12), 2505-2513. http://dx.doi.org/10.1007/s11269-008-9393-y.

Han, J. H. (2009). Food safety and innovative food packaging. Microbiologically Safe Foods. In H. Heredia, I. Wesley, \& S. García (Eds.), Microbiologically safe foods. Hoboken: John Wiley \& Sons. 
Han, S., Roy, P. K., Hossain, I., Byun, K., Choi, C., \& Ha, S. (2021). COVID-19 pandemic crisis and food safety: Implications and inactivation strategies. Trends in Food Science \& Technology, 109, 25-36. http://dx.doi.org/10.1016/j.tifs.2021.01.004. PMid:33456205.

Hascelik, G., Akan, Ö. A., Diker, S., \& Baykal, M. (1991). Campylobacter and enterohaemorrhagic Escherichia coli (EHEC) associated gastroenteritis in Turkish children. Journal of Diarrhoeal Diseases Research, 9(4), 315-317. PMid:1800562.

Imathiu, S. (2017). Street vended foods: potential for improving food and nutrition security or a risk factor for foodborne diseases in developing countries? Current Research in Nutrition and Food Science Journal, 5(2), 55-65. http://dx.doi.org/10.12944/CRNFSJ.5.2.02.

Iqbal, J., Khan, Z. H., \& Khalid, A. (2017). Prospects of robotics in food industry. Food Science and Technology, 37(2), 159-165. http:// dx.doi.org/10.1590/1678-457x.14616.

Ji, S., Li, X., Ma, Y., \& Cai, H. (2000). Optimal tolerance allocation based on fuzzy comprehensive evaluation and genetic algorithm. International Journal of Advanced Manufacturing Technology, 16(7), 461-468. http://dx.doi.org/10.1007/s001700070053.

Kamboj, S., Gupta, N., Bandral, J. D., Gandotra, G., \& Anjum, A. (2020). Food safety and hygiene: a review. International Journal of Chemical Studies, 8(2), 358-368. http://dx.doi.org/10.22271/ chemi.2020.v8.i2f.8794.

Karch, H., Tarr, P. I., \& Bielaszewska, M. (2005). Enterohaemorrhagic Escherichia coli in human medicine. International Journal of Medical Microbiology, 295(6-7), 405-418. http://dx.doi.org/10.1016/j. ijmm.2005.06.009. PMid:16238016.

Karimi, M., Sadeghi, R., \& Kokini, J. (2018). Human exposure to nanoparticles through trophic transfer and the biosafety concerns that nanoparticle-contaminated foods pose to consumers. Trends in Food Science \& Technology, 75, 129-145. http://dx.doi.org/10.1016/j. tifs.2018.03.012.

Kennedy, J., Jackson, V., Blair, I. S., McDowell, D. A., Cowan, C., \& Bolton, D. J. (2005). Food safety knowledge of consumers and the microbiological and temperature status of their refrigerators. Journal of Food Protection, 68(7), 1421-1430. http://dx.doi.org/10.4315/0362028X-68.7.1421. PMid:16013380.

Khalili, M., \& Sharifi-Mood, B. (2016). Hepatitis a virus infection. International Journal of Infection, 4(1), e38666.

Kumar, A., \& Kaur, J. (2011). A new method for solving fuzzy linear programs with trapezoidal fuzzy numbers. Journal of Fuzzy Set Valued Analysis, 2011, 1-12.

Kumar, V., Bhatia, M., \& Kumar, A. (2020). Microbes from mouth to gut impacting probiotics to antibiotics. Journal of Natural Science, Biology, and Medicine, 11(2), 83.

Lee, H., \& Yoon, Y. (2021). Etiological agents implicated in foodborne illness world wide. Food Science of Animal Resources, 41(1), 1-7. http://dx.doi.org/10.5851/kosfa.2020.e75. PMid:33506212.

Malla, S., \& Brewin, D. G. (2020). An economic account of innovation policy in Canada: a comparison of canola, wheat, and pulses. AgBioForum, 22(1), 25-36

Marriott, N. G., Gravani, R. B., \& Schilling, M. W. (2006). Principles of food sanitation. Boston: Springer.

Matle, I., Pierneef, R., Mbatha, K. R., Magwedere, K., \& Madoroba, E. (2019). Genomic diversity of common sequence types of Listeria monocytogenes isolated from ready-to-eat products of animal origin in South Africa. Genes, 10(12), 1007. http://dx.doi.org/10.3390/ genes10121007. PMid:31817243.

McNeill, F. M., \& Thro, E. (2014). Fuzzy logic: a practical approach. Saint Louis: Academic Press.
Medeiros, L. C., Kendall, P., Hillers, V., Chen, G., \& DiMascola, S. (2001). Identification and classification of consumer food-handling behaviors for food safety education. Journal of the American Dietetic Association, 101(11), 1326-1339. http://dx.doi.org/10.1016/S00028223(01)00318-2. PMid:11716314.

Mishra, B. P. (2008). Water pollution and food contamination in relation to health hazards: food safety as a global challenge. Pollution Research, 27(3), 395-400.

Nayak, R., \& Waterson, P. (2019). Global food safety as a complex adaptive system: key concepts and future prospects. Trends in Food Science \& Technology, 91, 409-425. http://dx.doi.org/10.1016/j. tifs.2019.07.040.

Ramos, M. O., da Silva, E. M., \& Lima-Júnior, F. R. (2020). A fuzzy AHP approach to select suppliers in the Brazilian food supply chain. Production, 30, e20200013.

Schroeder, K., Kubik, M. Y., Sirard, J. R., Lee, J., \& Fulkerson, J. A. (2020). Sleep is inversely associated with sedentary time among youth with obesity. American Journal of Health Behavior, 44(6), 756-764. http://dx.doi.org/10.5993/AJHB.44.6.2. PMid:33081874.

Seising, R. (2019). Lotfi Zadeh: fuzzy sets and systems. In R. Moreno-Díaz, F. Pichler, \& A. Quesada-Arencibia (Eds.), International Conference on Computer Aided Systems Theory (pp. 101-108). Cham: Springer.

Shongwe, M. I., Maseko, T., \& Vilane, B. R. (2020). Application of fuzzy cognitive mapping in the analysis of small earth dam failure. Journal of Water and Land Development, (44), 136-142.

Shuval, H. (2003). Estimating the global burden of thalassogenic diseases: human infectious diseases caused by wastewater pollution of the marine environment. Journal of Water and Health, 1(2), 53-64. http:// dx.doi.org/10.2166/wh.2003.0007. PMid:15382734.

Singh, S., Singh, N. P., \& Rani, R. (2020). hazardous elements in aqueous leachates of coal fly ash around thermal power plants disposal area. European Chemical Bulletin, 9(10-12), 360-365. http://dx.doi. org/10.17628/ecb.2020.9.360-365.

Smith, A. M., Tau, N. P., Smouse, S. L., Allam, M., Ismail, A., Ramalwa, N. R., Disenyeng, B., Ngomane, M., \& Thomas, J. (2019). Outbreak of Listeria monocytogenes in South Africa, 2017-2018: laboratory activities and experiences associated with whole-genome sequencing analysis of isolates. Foodborne Pathogens and Disease, 16(7), 524-530. http://dx.doi.org/10.1089/fpd.2018.2586. PMid:31062992.

Sonchieu, J., Azouline, M., \& Ngassoum, B. M. (2018). Investigation on five years (2010-2014) food poisonings recorded in Bamenda and NDOP public hospitals in Cameroon. Insights Biomed, 3, 9-16.

Tirado, M. C., Cohen, M. J., Aberman, N., Meerman, J., \& Thompson, B. (2010). Addressing the challenges of climate change and biofuel production for food and nutrition security. Food Research International, 43(7), 1729-1744. http://dx.doi.org/10.1016/j.foodres.2010.03.010.

Vadiati, M., Nalley, D., Adamowski, J., Nakhaei, M., \& AsghariMoghaddam, A. (2019). A comparative study of fuzzy logic-based models for groundwater quality evaluation based on irrigation indices. Journal of Water and Land Development, 43(1), 158-170. http://dx.doi.org/10.2478/jwld-2019-0074.

Vasanthi, S., \& Bhat, R. V. (1998). Mycotoxins in foods-Occurrence, health \& economic significance \& food. The Indian Journal of Medical Research, 108, 212-224. PMid:9863277.

Walls, H., Baker, P., Chirwa, E., \& Hawkins, B. (2019). Food security, food safety \& healthy nutrition: are they compatible? Global Food Security, 21, 69-71. http://dx.doi.org/10.1016/j.gfs.2019.05.005.

Wang, G., \& Li, J. (2017). Approximations of fuzzy numbers by step type fuzzy numbers. Fuzzy Sets and Systems, 310, 47-59. http:// dx.doi.org/10.1016/j.fss.2016.08.003. 
Wertheim-Heck, S., Raneri, J. E., \& Oosterveer, P. (2019). Food safety and nutrition for low-income urbanites: exploring a social justice dilemma in consumption policy. Regional environmental change, 31(2), 397-420. http://dx.doi.org/10.1177/0956247819858019. PMid:32704235.

Zadeh, L. A. (1983). Commonsense knowledge representation based on fuzzy logic. Computer, 16(10), 61-65. http://dx.doi.org/10.1109/ MC.1983.1654199.

Zadeh, L. A. (1995). Discussion: probability theory and fuzzy logic are complementary rather than competitive. Technometrics, 37(3), 271276. http://dx.doi.org/10.1080/00401706.1995.10484330.
Zadeh, L. A. (1996a). Fuzzy sets. In G. J. Klir, \& B. Yuan (Eds.), Fuzzy sets, fuzzy logic, and fuzzy systems: selected papers by Lotfi A Zadeh (pp. 394-432). Singapore: World Scientific. http://dx.doi.org/10.11 42/9789814261302_0021.

Zadeh, L. A. (1996b). Soft computing and fuzzy logic. In G. J. Klir, \& B. Yuan (Eds.), Fuzzy sets, fuzzy logic, and fuzzy systems: selected papers by Lotfi A Zadeh (pp. 796-804). Singapore: World Scientific. http://dx.doi.org/10.1142/978 9814261302_0042.

Zimmermann, H. (2011). Fuzzy set theory-and its applications. Dordrecht: Springer Science \& Business Media. 